\title{
Editorial
}

\section{$A$ Constitution for Europe and Other Constitutions}

The spring of 2005 saw major set-backs for the Treaty of Rome of 29 October 2004, establishing what it calls 'a Constitution for Europe'. On 29 May, the French rejected the Treaty in their referendum by $54,8 \%$ (turnout 70\%). Then the Dutch rejected it on 1 June by an even more massive 61,7\% (turnout 63\%). In response to these refusals the member states agreed to a 'reflection period' and a suspension of the ratification deadline at the European Council of 16 and 17 June. In the subsequent 10 July Luxembourg referendum $56,2 \%$ of the electorate voted in favour (obligatory vote), a significant drop from polls in October 2004, but at least creating a simple majority of 13 member states to ratify the document. But the UK put its ratification on hold, followed by other countries.

Outright rejection by two member states' populations in a turnout far exceeding that at elections for the European Parliament (France 43,1\%, NL 39.1\%) and the fact that even in Luxembourg the text for a Constitution of Europe did not receive the majority one would have expected a few months ago, give food for thought.

Many different motives have inspired the negative votes, but the same goes for the affirmative ones. These may not relate to the substance of the Constitution as proposed, nor even to the constitutional project as such. Similarly, we see a plethora of explanations for the 'no'-votes: from the governments failing in their campaigns to the Union failing to relate to the citizens, the citizens failing to understand the Union or the proposed texts, the academic and political elites failing to live up to their responsibilities, the text being too complicated for the ordinary citizen, and so on. The motives for the 'no' do not necessarily have a bearing on either the text or the project of the Constitution. Nor, however, do they have a necessary bearing on the turn given to European integration by the no votes.

What turn may be in store? One possibility is for the single formal act of entrenching the foundations, principles and 'rules of the game' into one single consolidated Constitution to become less important. Possible scenarios include increasing 'variable geometry', with member states opting in and out of parts of treaty regimes, the conclusion of protocols to be annexed to the present Treaties in 
order to anchor fundamental rights or other bits and pieces into a binding instrument. Together these documents will make up a provisional constitution and there is nothing more definitive than the provisional - as the German Grundgesetz [Basic Law], putatively a merely provisional text to be followed up by a full-fledged Verfassung [Constitution], teaches us.

No doubt, a definitive rejection would be a lost occasion for the European Union to articulate itself as a political community. This is what will be regretted most, also by those who had justifiable legal objections to parts and particulars of the document. It is this lost occasion which may explain the crisis in which the no seems to have steeped the Union's institutions and its watchers alike. The sense of loss even among mere lukewarm supporters confirms that it is not the text which really counts. Once we realise this, a further insight is possible.

What is rejected is only ' $a$ Constitution for Europe', as the Treaty names itself. Europe has many more. There are, of course the national constitutions on which the Union will always remain founded in part. This may not follow from the legal rules viewed in isolation. The proclaimed 'primacy' of EC law is only one aspect of the situation. It derives its particular flavour from the context of national constitutional practices and understandings which themselves claim some form of political and constitutional primacy. The same holds true for many other constitutional notions in the European Union, such as legislation, liberty and freedom(s), rights.

At the European plane there is, and will be, the constitution in the broader sense, the substantive constitution. In national constitutional scholarship we know that this is essential for reading and understanding the formal constitution. Likewise the search for the 'hidden constitutional script' should become the daily business of constitutionalists with an interest in the European Union.

So European Union may not end up with a single Constitution carrying that name. But that is no novelty and no problem; it might even be called typically European. Many modern constitutions are indeed designer's blueprints, like notably the American Constitution. In Europe, while there are some of this sort, such as the German and Italian, others are essentially rooted in incremental historical development. The British and arguably the Dutch and - until recently some of the Scandinavian constitutions are of the latter type. The European Union, with or without its 'a Constitution', is bound to belong to that British school. Piecemeal adoption and initial rejections are all in the game, as are responses to political events in the world outside the texts themselves. Responses to the horrors of the Second World War, to the horrors of 40 years of communist repression, to the Cold War and to the recent forms of cowardly terrorist attacks may have a stronger impact than the adoption of any particular text. 
In the substantive constitution, containing its responses to major events, a political community articulates itself. Without such events and responses, we would not be able to speak of a constitution of Europe at all. Clearly, this requires less of the black letter approach to single constitutional instruments. It requires, in short, a more 'European' approach to the constitution of Europe.

$A$ Constitution for Europe may have nearly died, long live the Constitution of Europe.

LFMB/WTE 